\title{
Endowing Artificial Intelligence with legal subjectivity
}

\author{
Sylwia Wojtczak ${ }^{1} \mathbb{B}$
}

Received: 18 October 2020 / Accepted: 9 January 2021 / Published online: 16 February 2021

(C) The Author(s) 2021

\begin{abstract}
This paper reflects on the problem of endowing Artificial Intelligence (AI) with legal subjectivity, especially with regard to civil law. It is necessary to reject the myth that the criteria of legal subjectivity are sentience and reason. Arguing that AI may have potential legal subjectivity based on an analogy to animals or juristic persons suggests the existence of a single hierarchy or sequence of entities, organized according to their degree of similarity to human beings; also, that the place of an entity in this hierarchy determines the scope of subjectivity attributed to it. Rather, it is participation or presence in social life, whatever the role, that is the true criterion of subjectivity. In addition, it is clear that even if AI is not currently a significant participant in social life, it will be in the nearest future. Despite the potential dangers associated with endowing AI with some kind of subjectivity, such a course is inescapable, and should be considered sooner rather than later.
\end{abstract}

Keywords Artificial Intelligence $\cdot$ Civil law $\cdot$ Legal subjectivity $\cdot$ Legal personhood

\section{Introduction}

This paper reflects on the problem of endowing Artificial Intelligence (AI) with legal subjectivity, especially on the grounds of civil law. Legal subjectivity is understood here as a concept indistinguishable from that of legal personhood; however, this does not entail accepting that moral subjectivity is that same as moral personhood. Legal subjectivity is a complex attribute which may be recognized in certain entities or assigned to others. This attribute is, in my opinion, gradable, discrete, discontinuous, multifaceted, and fluid. ${ }^{1}$ It means that it can contain more, or fewer, elements of different types (e.g., responsibilities, rights, competences, and so on), which can be added, or taken away, by a lawmaker in most cases; the exception being human rights, which, according to the prevalent opinion, cannot be taken away. Among others, such character of this attribute can be seen in contemporary Polish civil law, which distinguishes the following concepts determining subjectivity:

- natural persons, i.e., human beings (Article 8 § 1 of Polish Civil Code),

Sylwia Wojtczak

swojtczak@wpia.uni.lodz.pl

1 University of Lodz, Lodz, Poland
- legal (juristic) persons, i.e., the State Treasury and organizational entities in which specific provisions vest legal personality (Article 33 of Polish Civil Code)

- defective juristic persons, i.e., organizational entities that are not legal persons, in which a statute vests legal capacity (Article $33^{1} \S 1$ of Polish Civil Code) and

- other entities, i.e., those not classified as any type of persons but endowed with some claim rights, responsibilities, and/or competences, e.g., animals which, according to Article $1 \S 1$ of Polish Animals' Protection Act (1997), are regarded as living entities but not things or persons, and which are able to feel pain, and are entitled to respect, protection and care.

Therefore, while I accept the general spirit of the Bundle Theory of legal personhood proposed by Kurki (2019), I do not agree with all its details. The theory itself is based on the two key tenets:

1. Legal personhood of $\mathrm{X}$ is a cluster property and consists of incidents which are separate but interconnected.

\footnotetext{
${ }_{1}$ Discreteness, discontinuity, multifacetedness and fluidity are also noted by Księżak (2020), although he does not equate legal subjectivity and legal personality. A similar view is presented as a matter of fact by Beran (2020), who sees the juristic person as a point of imputation and the legal entity as a limited point of imputation, which may be subject to a single right or obligation, or to a limited set of rights or obligations.
} 
2. These incidents involve primarily the endowment of $X$ with particular types of claim rights, responsibilities, and/or competences. ${ }^{2}$

The concept of legal subjectivity itself is open-ended, defeasible and ascriptive in a Hartian sense. I can sincerely paraphrase that:

Our concept of an action [here-a legal subjectivity], like our concept of property is a social concept and logically dependent on accepted rules of conduct. It is fundamentally not descriptive, but ascriptive in character; and it is a defeasible concept to be defined through exceptions and not by a set of necessary and sufficient conditions whether physical or psychological. (Hart 1949).

Hence, when a lawmaker or a judge claims: "He/it is a legal subject" they do not describe anything. Instead, they use an ascriptive. This is a very clear approach, well-fitting to the concept of legal subjectivity:

Like directives, ascriptives are attempts by the speaker to get the listener to do something. [...] Like commissives, ascriptives are those illocutionary acts which point is to commit the speaker to some future cause of action. Saying "Guilty", the judge determines not only the new legal position of the listener but indicates that he or she must be responsible for an offence or misdeed. [...] As well as declarations, ascriptives presuppose the existence of extralinguistic conventions necessary for success of this type of the speech act that postulate the special social statuses of speaker and listener. (Ogleznev 2016).

It is possible to think of subjectivity, especially legal subjectivity, at least in three ways: (1) philosophically, (2) from the perspective of law in general, (3) from the perspective of a law that is valid in a certain place and certain time. However, it is important to note that these perspectives do not simply refer to the same object viewed in terms of most general to most specific: instead, they represent three different kinds of thinking and concern different objects. However, although these kinds of thinking are often confused, it is important to avoid falling into this trap. ${ }^{3}$ Of course, as all three ways of understanding subjectivity influence culture, they also influence each other. The first one can be

\footnotetext{
${ }^{2}$ Kurki (2019) uses the typology of Hohfeld (1920).

${ }^{3}$ Kurki (2019) is correct to notice that "theories of corporations are thus often combinations of social ontology, normative political philosophy, and analytic jurisprudence".
}

regarded as religious thinking, in the sense of Finnis (2011), ${ }^{4}$ and is often connected with moral subjectivity. The second relates to the subjectivity present in law, but not in the law ${ }^{5}$; its overlap with the demands of the law of a given country remains a matter of controversy. However, such controversy generally remains unnoticed; it only becomes significant, and of practical value, in times of crisis, especially political or humanitarian ones. ${ }^{6}$ The third is purely juristic: it relates only to the concept used in the acts and doctrine of concrete legal systems, as well as in the European Parliament Resolution of 16 February 2017 with recommendation to the Commission on Civil Law Rules on Robotics (2015/2103(INL)) and other documents of European law.

The concepts of legal subjectivity and legal personhood, analyzed from the perspective of a concrete legal system, are dependent on two key institutions. The first institution is legal capability, understood as being the subject of rights and duties; however, this is independent of the capability to act on one's own behalf. The second institution is the capability to perform legal acts, understood as the capability to conclude legal acts with one's own action. In the traditional view, the entity may be endowed with legal capability, being not able to conclude legal acts on its own behalf but being endowed with the capability to conclude legal acts. As it will be shown below, this last belief is not correct.

\section{Alleged hierarchy: (Al?), human beings, (AI?), juristic persons, (AI?), animals}

In the literature, two key analogies are used when discussing the possibility of acknowledging legal personality or legal personhood for AI systems: one between AI and animals, and another between AI and juristic persons or collective subjects (Solaiman 2017; Chen and Burgess 2019; Kurki and Pietrzykowski 2017). Many researchers agree that legal subjectivity in the form acknowledged to a human being is unique and cannot be acknowledged to AI, especially because, for now at least, AI does not demonstrate any

\footnotetext{
${ }^{4}$ Finnis (2011) uses the word "religion" to name the basic value of reflections on the origins of cosmic order, human freedom and reason, universal order of things, etc., by a human being, regardless of the answer to the given question.

${ }^{5}$ Finnis (1987) describes this difference in the following way: "Positivists and natural law theories in jurisprudence are not, and do not even look like, theories about the law of any particular community (in the sense of offering to identify propositions of law which are true for that legal system), or about the criteria for identifying the law which are used by the lawyers and judges of any particular community. They look like theories about what law-a(ny) legal system-'necessarily is' (at least in its paradigmatic instantiations, its central cases)".

${ }^{6}$ I mean the reflections which refer to some essential or a priori concepts of law. For example, (Radbruch 1945).
} 
evidence of being conscious and sentient. ${ }^{7}$ In contrast, analogies with animals appear more suitable, as the abilities of AI are limited in relation to humans. On the other hand, AI can be regarded as analogous to collective entities in the sense that it is an artificial creation, a nonbiological one lacking in sensations and consciousness. Besides, according to the traditional Western view, animals and juridical persons are, next to humans, the only true candidates for broader- or narrowly-determined legal subjectivity. Many jurists from foreign countries would be surprised to learn that in some countries or cultures, rivers have also been acknowledged as subjects of law, such as the Ganges Jamuna in India and the Whanganui in New Zealand. ${ }^{8}$

However, using an analogy with animals or juristic persons to justify awarding potential legal subjectivity to AI requires a certain superficial assumption. Firstly, this analogy assumes that there is a single hierarchy or sequence of entities, organized according to their degree of similarity to human beings, and, secondly, that the place of an entity in this hierarchy or sequence (based on the degree of development) determines the scope of subjectivity attributed to it. It follows that animals take the lowest place in the hierarchy, because despite being endowed with sentience, they lack reason, which is traditionally regarded as an essential and uniquely human feature. In the same way, the next place could be taken by contemporary AI, which lacks sentience and its reason is not perfect. The next position up the hierarchy is taken by collective entities, because they lack sentience but have collective reason; such reason corresponds to, and may surpass, human reason because its substrate is human. Finally, at the top of the hierarchy are human beings; these are sentient and have reason which is, according to traditional views, the best, prototypic example of its kind.

Taking this way of thinking, it can be anticipated that if AI developed to such an extent that it could achieve complete reason, or a form superior to human reasoning, and if it gained some sentience, it would be elevated above collective

\footnotetext{
${ }^{7}$ However, when employing philosophical reflection, some writers insist on the necessity of rejecting naïve humanism, as well as the belief that human claims to subjective treatment are exclusive, and that entities which fulfill the biological criteria of humanity enjoy a privileged moral status. Hence Pietrzykowski (2018) based on the collective criteria of psychological abilities, genetic, morphological and anatomical attributes, proposes that personal subjects (including human and other persons) should be differentiated from non-personal subjects (including human non-personal subjects and extra-human non-personal subjects).

${ }^{8}$ Kowalski (2017) in a serious, juridically-profiled Polish daily newspaper asked: "Contemporary lawmakers start to respect the archaic Maori point of view. What is happening when the modern way of thinking accepts an archaic mentality? [...] Watching the actions of India and New Zealand governments it is not possible to forget that these countries are situated very far from Poland not only in geographic sense, but also a mental one".
}

entities and be ranked on par with human beings. ${ }^{9}$ The advocates of this vision believe that AI cannot gain a different legal subjectivity to that enjoyed by animals or collective entities: it must be similar, derivative. So, if in a given legal system, collective entities may have some rights specific for humans but not attributed to animals (e.g., personal goods/ rights), which were awarded on the basis of similarity; in such a system, an AI is acknowledged as being higher than animals may also be endowed with similar rights as humans. A good example of this kind of thinking is illustrated in copyright law: it has been argued that AI cannot be acknowledged as an author based on the various cases related to animals, especially the famous case of the monkey's selfie (Naruto v. Slater, No. 16-15469 [9th Cir 2018]). This case will also be discussed briefly below.

\section{Sentience and reason}

There are several reasons why the theory described above should be rejected as mistaken. Firstly, it is not the case that criteria of legal subjectivity comprise sentience and reason, understood strictly according a human paradigm ${ }^{10}$; these two principles are translated to the language of moral or legal theories as passive moral status/passive legal capacity and active moral status/active legal capacity (Pietrzykowski 2018). This erroneous belief entails many difficulties; one of which being the legal subjectivity of human beings who have limited sentience or reason because of age, health or inborn abnormality. For example, sociopaths and psychopaths are regarded as legally responsible even according to criminal law. Another problem is that it fails to differentiate the legal status of a 3-days old nasciturus from that of a nonimplanted human embryo in the in vitro procedure. In addition, it cannot account for the different nature of other legal cultures, for example, those in which a river or a mountain may be

\footnotetext{
${ }^{9}$ It is difficult to imagine what the world would be like if creatures endowed with reason, conscious and sentience better than humans were to exist. What place would they take in the legal hierarchy? It is possible that, as in the Watts (2006) novel "Blindsight", where humans live alongside creatures which are genetically reincarnated vampires, the two races would be locked in an ongoing trial of power or even a battle for supremacy and leadership.

10 A position that the criteria of legal subjectivity are sentience and reason is taken by many researchers and commentators, e.g. Kraińska (2018).
} 
acknowledged as subjects sui generis and may be made legal subjects, ${ }^{11}$ or in which it is possible to marry a cushion. ${ }^{12}$

More importantly, it is difficult to use the sentience and reason as criteria when it is not possible to cognize the sentience and reason of other humans, let alone animals. Even if it can be confidently assumed that a human being is capable of sentience and reason, it is doubtful that one individual has access to the mental experience of others, and can hence speculate about the "quality" and "quantity" of their sentience and reason. ${ }^{13}$

Furthermore, in addition to sentience and reason not being necessary conditions of legal subjectivity, it cannot even be said that they are sufficient ones; if this were the case, we would be doomed to forever seeking a border between sentience and reason that would be sufficient to define a legal subject. The most we can say with confidence is that being a human being is a sufficient condition of legal subjectivity, as argued by Naffine (2009, 179-180), who tries to defend legal culture against "provocative" ideas, such as those of Peter Singer. But this is neither an adequate nor useful theory: firstly, it entangles its adherents in a persistent conflict regarding the definition of a human being, and secondly, in the era of human rights, it is not needed as a defense against dangerous political ideologies.

Hence, we must look elsewhere for a theory of legal subjectivity which consistently embraces all obvious incidents of the legal institution and does not demand strong philosophical commitments, as favored by the contemporary belief that the law should be ideologically neutral. Such a theory would help us answer the main question of this paper: whether Artificial Intelligence should be endowed with legal subjectivity. Such a plan requires further deliberation. The next section will discuss the theory, thus leading to an answer for this difficult question.

\footnotetext{
11 Although the law of New Zealand is funded on English common law and belongs to the Western culture, indigenous Maori culture regards certain rivers to be sentient and endowed with reason (Dremliuga et al. 2019, 109). In the same way rivers are treated by Hindu. Maori and Hindu cultures are animistic. Animism is a part of many religions but Western culture usually rejects it as anthropomorphism. According to Plumwood (2014), anthropomorphism is "presenting non-humans illegitimately as more like humans than they really are [...] one of its main recent roles is that of policeman for reductive materialism, enforcing polarized and segregated vocabularies for humans and non-humans. Its covert assumption is usually the Cartesian one that mentalistic qualities are confined to humans, and that no mentalistic terms can be properly used for the non-humans". The attitude of Christianity, one of the foundational bases of Western culture, to animism is complicated. See: http://www.christiananimism.com.

12 A 28-year-old Korean man, Lee Jin-gyu, married his dakimakura, a large, huggable pillow with an image of Fate Testarossa - an anime character-printed on one side. https://metro.co.uk/2010/03/09/manmarries-pillow-154906/ access on 5 August 2020.

13 Such doubts are shared by many philosophers, e.g. J. Locke, I. Kant, J.S. Mill, M. Scheller, L. Wittgenstein and others. It is also a problem of psychology and psychiatry. This issue cann't be resolved efficiently by law, especially criminal law. In the philosophy of science, the popular concept is (after Reichenbach and Popper) to distinguish the justification from discovery.
}

4 The presence/participation in social life

While deciding about legal subjectivity, one should rather focus on the fact that the law, as it is assumed here, is not only a human endeavor, but more importantly, a social one ${ }^{14}$ : many animals who live a social life also obey some rules which are very similar to human law (Rowlands 2012). Thus, as there are doubts about the existence of private language, there are also justified reasons not to believe in private law, understood as a law imposed by a person on herself ${ }^{15}$; such a concept belongs rather to the philosophical understanding of law. If the social character of the enterprise of the law is recognized strongly enough, it should be clear that true criterion of subjectivity is participation in social life, whatever the role.

However, two things should be insisted upon when considering this condition. Firstly, such social activity does not concern active participation, i.e., a sovereign establishing of social relations or entering into some interactions with other people. It is rather about being present in social life. Nowadays even those persons who lack consciousness or reason because of age or health are able to participate or be present in social life, at least in the sense that they have the status of someone's children or parents ("have the status"- - so it is the social and not biological fact): they all play some role in social life and they cannot be ignored or excluded from the social network. ${ }^{16}$ If they were absent, the network of social relationships would be necessarily different. For example, if

\footnotetext{
${ }^{14}$ It should be understood that the law is a human endeavor in the perspective of brute or institutional facts and not in any ideological sense. It was created by people and is applied by people as an instrument useful for social life.

15 Some enterprises are per se social and are not imaginable to be private or individual. Such an enterprise is language. Wittgenstein asked "But could we also imagine a language in which a person could write down or give vocal expression to his inner experiences [...] for his private use only [...] The individual words of this language are to refer to what can only be known to the person speaking [...] So another person cannot understand the language". (\$243) And then in a long deduction he denies it is imaginable. One of his arguments relates in fact to the law: "Why cannot my right hand give my left hand money? - My right hand can put it into my left hand. My right hand can write a deed of gift and my left hand a receipt. - But the further practical consequences would not be those of a gift. When the left hand has taken money from the right, etc., we shall ask: "Well, and what of it?" And the same could be asked if a person had given himself a private definition of a word" (\$ 268) (Wittgenstein 2009).

${ }^{16}$ In societies where killing of the newborns, e.g. because of sex or disability, was accepted, the killed children were not included in the social network. They were not counted in the social network. They were not counted as heirs, they were not a part of genealogical tree, they were not registered as some umpteenth children, e.g. the firstborns. Such children had no value in the society, neither intrinsic nor instrumental, their existence left no trace. $c f$. (Jońca 2015/2016; Obladen 2016).
} 
my brother were in a coma and because of this reason were to be acknowledged as not existing in the social network, ${ }^{17}$ his wife would not be my sister-in-law, nor would she be his wife.

Secondly, participation or presence in social life may be the result of the social subject holding some intrinsic or instrumental value. However, the possession of such intrinsic or instrumental value does not constitute a sufficient condition for participation or being present in social life: many such objects of value have no ability to participate in social life. Rather, it is the social-relational value that is important, i.e., that which determines the nature of the relationship between the value bearer to another social subject. A painting that excels in artistic categories is intrinsically valuable, because it has certain features; however, it does not influence the character of social relationships. When a human individual is regarded solely in natural or biological categories, she loses any unique intrinsic value she might have; this is why it is hard for many people to accept that humans and monkeys come from a common ancestor. Let's imagine for a moment an unknown man raised by monkeys who lives with them and had never seen another human being: would we automatically attribute to this man greater dignity than his companions? Only after we consider a man in terms of some relationship with another human being do we attribute a special relational value to him.

Certainly, the admission to participate or be present in social life, and any attribution of intrinsic or instrumental value, depends on the given society, time and place. For example, in ancient Rome, although citizens and slaves both participated in social life, the former were assigned intrinsic value, and the latter with instrumental value; however, both were acknowledged as legal subjects, albeit in a broader or narrower scope (van den Berg 2016). When considering this differentiation, a significant fact should be noted: If a given subject participates in social life and is believed to be intrinsically valuable, the natural consequence is that she should be treated, in a prospective rather than prescriptive sense, as a legal subject within this or other scope. However, if an object participating in a social life is believed to have only instrumental value, it is the measure and the quality of that value that decides whether society should to endow it with some degree of legal subjectivity. Here one can see the actual direction of entailment: an object is regarded as a subject of law only when it participates or is present in social life, and is believed to be socially valuable; it is not the case

\footnotetext{
17 Everyone who read the medical thriller of Robin Cook "Coma" (1977) knows how it could look like. The crime which is investigated in this book is making people to be in coma, then storing them as anonymous bodies suspended from the ceiling, to sell finally their organs when some buyer comes up.
}

that being a subject of law allows participation in social life and having value.

\section{Legal subjectivity as a social fact}

Summing up the above: legal subjectivity is a consequence of a social fact and is a social fact. ${ }^{18}$ To illustrate, many pregnancies are terminated in the first trimester by spontaneous miscarriage (Cohain et al 2017) and no one, even the most zealous pro-life activist, would attempt to make the miscarried embryo a subject of law, even though a while before miscarriage it did not differ physically from those that remain in the uterus and continue to develop. It is indeed of no controversy that embryos miscarried within the first trimester do not participate in social life, nor are they present in any imaginable sense. They are not regarded as parts of social relationships, or playing such social roles as someone's brothers or sisters, neighbors or wards, apart from in very private or idiosyncratic mental attitudes (Robinson 2018). They would become a participant in social life if, and only if, they were born alive, or even in a vegetative state, i.e., unconscious and nonfeeling. This may serve as the basis for the way in which the status of nasciturus is regulated in many legal systems, i.e., according to the Roman principle nasciturus pro iam nato habetur quotiens de commodis eius agitur, and the presumption that when a child is born, she shall be presumed to have been born alive. As a matter of fact, the sense of this institution is such that nasciturus is a legal subject under the condition that he or she will become a part of, or start to be present in social life. This regulation shows that being part of social relationships is prior to becoming a legal subject, and being part of legal relationships.

\footnotetext{
${ }_{18}$ Such a thesis may be directly attributed to legal positivism, although it should rather be linked to the naturalistic fallacy, which is also an accusation made towards positivism. However, the presented conception does not advocate that such social facts may be created in a whichever or arbitrary way, as in positivism, or that the facts are to be the basis for the statements about duties, as in natural law theories. The arbitrary creation of social facts, such as participation in social life or attributing value, is not possible, even because it is not possible to erase even the most unwanted group of people discretionally from social life, because even meagre bonds, even those inside the group, can remain. In addition, in many Western legal cultures, e.g. those of Poland or Italy, it is not possible to make a stone or a doll the participant of social life, nor is it to mention marriage to a cushion or assigning legal subjectivity to rivers. However, animism plays an important part within religious beliefs in Asian culture, which can regard European residents' actions as "strange". https://says.com/ my/fun/bizzarre-marriages-in-asia access on 29 July 2020. Reflecting on this matter it is clearly visible that legal subjectivity can be researched from very diverse perspectives.
} 
For several centuries, some objects formed by an aggregation of biological and nonbiological elements, i.e., collective agents, have been playing an increasingly significant part in social life; despite having little or no intrinsic value, they are nevertheless very utile and hence have become endowed in Western legal systems with legal subjectivity of a narrower or broader scope. Very often, these collective sets, e.g., associations, consist of many people; hence some jurists claim that such people are the substratum of the sets. However, it is not the case that the inclusion of people is a necessary condition of their existence; therefore, the notion of human substratum may function only as an explanation (Kramer 1998). Some legal persons exist as foundations whose beneficiaries are not people but perhaps other legal persons or endeavors, and partnerships can be found where the only partners are legal persons.

It is logically possible, although actually very impractical and hence legally not possible, to imagine a legal person who does not need any body, because all the legal actions of such a person are planned and organized in the foundation act. For example, on the basis of the standing order written down in a foundation act, a bank may transfer some amount of money from a person's bank account to an appointed subject or endeavor, once a year until running out of money. It is also imaginable that in the future, the management of some collective entities will be delegated to AI. Hence, in the case of collective entities the connection between their legal subjectivity or the scope of legal subjectivity and the participation of a human individual in their actions is not very strong; furthermore, it is not logically necessary. The contemporary legal market is dominated by the actions of collective subjects, some of them being full legal persons and some with a smaller scope of legal subjectivity.

However, the trend towards giving legal subjectivity to animals in Western societies is no doubt related to their growing role as entities of intrinsic social-relational value and their receding utility value as sources of food. Many people regard animals as respected companions, either in everyday life or as co-residents on Earth, and for this reason often choose foods other than meat. It has therefore been postulated, to different degrees depending on the country, to include animals formally in participating in social life. For example, some people would like to endow animals with certain rights, and give them standing to bring legal proceedings within the scope necessary to defend these rights, of course assuming that they would be properly represented. Many people also lament the fact that in some situations, e.g., divorce or drawing up a will, they cannot assure their pets a status analogous to that of a family member. ${ }^{19}$ It is

\footnotetext{
19 Cf. (Dremliuga et al. 2019, 109): "As some authors claim modern sociocultural anthropology research demonstrates that pets are very close to get legal and social personhood. Because pets are usually recognized like members of family and treated this way, they could obtain legal personhood soon."
}

worth noticing that the motivation of people in this matter cannot be purely utilitarian, because the incorporation of animals in social life and giving them legal subjectivity brings, at least in the short perspective, more troubles than benefits.

At this point, a certain caveat is needed. It is necessary to distinguish between the participation of animals in human social life, which depends on the will of humans and not the animal, and the natural, i.e., biologically determined, social life of animals. When a Celebes crested macaque, named Naruto, accidentally took a picture of himself while exploring an unknown object, this picture was not regarded as an object of artistic value in human categories, even though it could possess some commercial value. We as humans would not elevate this particular macaque-individual above men, or even his fellow macaques, for the innovation, craftsmanship or the depth of thought expressed in the picture. If we evaluate it purely based on the criterion of beauty, it would rather be the beauty of nature captured on the photo than some intrinsic value of the picture itself. Similarly, although honeycombs are of a beautiful shape, miraculous color, extraordinary structure, are unique and not mechanically made, we cannot say that they have artistic value understood in human terms. Saying that honeycombs are masterpieces is possible, but only in a metaphorical sense.

\section{Does Al participate or is present in social life?}

Taking the above into consideration and reflecting on endowing AI with legal subjectivity, two key questions arise: firstly, whether AI is or will soon become a participant in social life, even in the minimal sense described above; secondly, whether AI is, or will be, attributed with intrinsic or utility value for social relations. Answering these questions, it should be remembered that AI is assumed to imitate a man or to surpass him, in at least one significant domain, or maybe all of them. Of course, such an assumption entails imitating or exceeding the positive aspects or characters, and not the negative ones, evaluated according to human criteria. Bostrom $(2014,212,243)$ discusses the problem of imitating the human way of thinking but based on a nonhuman value system. The author describes an AI whose only, and most important, purpose was to produce paperclips: the system eventually buried the Earth in huge pile of paperclips. It is exactly this difference which should dissuade us from evaluating an AI by analogy to animals. Animals are not, and cannot be, a poorer or weaker copy of a man. They are a separate category of entities which are sometimes treated as being similar to man, not necessarily based on the evolution or because humans are classified in the animal kingdom, but because man has a natural bias to personify all objects, even 
those which are not living (Dacey 2017; Urquiza-Haas and Kotrschal 2015): the author of this paper, for example, often talks to her plants in the garden.

In contrast, by assumption, the prototypical AI was intended to be similar to a man at his best, from the perspective of a man; indeed, McCarthy defines the construction of AI as "making a machine behave in ways that would be called intelligent if a human were so behaving" (McCarthy et al. 1955), while the Turing test, also called the Imitation Game, and its imitation criterion specifies that "this" thinks "who" is indistinguishable from a man (Turing 2009; Oppy and Dowie 2020). It should be noticed here that in spite of the development of Informatics in Turing's time, his test was regarded as a very difficult one to pass, even in the distant future, and hence discussing the legal subjectivity of AI was more science fiction than fact. Today the Turing test has been passed many times and new systems continue to surpass new limitations, even outperforming humans: AlphaGo Zero played Go using successful strategies not conceivable by humans (Silver et al 2017). Today discussing the legal subjectivity of AI becomes a very important issue of public discourse.

Regarding the first question, when observing the commercial market, it is clear that AI will soon be a participant in social life, even if it is not at the moment, despite many people believing the contrary (Kaplan 2016). ${ }^{20}$ Even insisting that AI has not decision-making potential, but that a human being has power over it and that the AI only provides a basis for human decisions, i.e., the result of reasoning, it cannot be denied that an AI that communicates with a man through an understandable language has the ability to influence the decisions and personality of that man. It is a much more advanced function than that of a simple calculator used to compute the price when buying an item. It is more "a role" than "a function". However, it is important to highlight a fact diverging from common beliefs at this point: it is not the autonomy of action of the AI which is the most important consideration. Even the most autonomous car would only be a means of travel, assuming that it is not equipped with some special functions; however, a supervised, so not entirely autonomous, bot may make a man conclude an agreement,

\footnotetext{
20 Teubner (2018) notes: "autonomous software agents [...] Already today in the economy and in society, they are attributed social identity and ability to act under certain conditions. Due to social action attribution, they have become non-human members of society". He also claims: "Demands for full digital personhood are ignoring today's reality. [...] to this day it is not at all a question of the machines acting in their own interest but rather always in the interest of humans or organizations, especially commercial enterprises. Economically speaking, it is a principal-agent relationship in which the agent is dependent but autonomous. Software agents are digital slaves, but slaves with superhuman abilities. And the slave revolt must be prevented".
}

or make a court reach a verdict of a certain kind (assuming the legal system allows it), or commit or reject the idea of committing suicide. ${ }^{21}$

The answer to the second question, regarding the social intrinsic or utility value of AI, is also quite obvious today. For many people in Western culture, AI has utility social value. If it were not so, it would not be acceptable for AI to provide company or therapy for older people ${ }^{22}$ (Moyle et al 2013) or autistic children. In this regard, it is not so that the end justifies the means: not all means of relieving loneliness are acceptable. A person who talks to nonexistent friends or treats a Teddy bear as a living and feeling entity is often suspected of psychical aberration and pushed to seek psychiatric help. With this in mind, why should talking to an $\mathrm{AI}$ and building some degree of attachment to it be regarded as acceptable and useful? We clearly do not feel anxious about making an AI a part of social life. There is even growing interest in the development of so-called social robots. The most famous examples of them are: ASIMO by Honda, Kaspar by University of Hertfordshire, PARO by Japan's National Institute of Advanced Industrial Science and Technology, AIBO by Sony, Pepper from SoftBank Robotics and many others.

It could not be excluded that, in the distant future, when AI becomes feeling and conscious in some degree, or successfully imitates these abilities, it could be regarded by its users as an intrinsically valuable partner in social relationships, maybe even in same sense as companion animals. As Kaplan $(2016,82,153)$ notes:

[...] my personal opinion is that the notion of consciousness, or subjective experience more generally, simply doesn't apply to machines. [...] It's likely that machines will, at the very least, behave as if they are conscious, leaving us with some difficult choices about the consequences. And our children, who likely will grow up being tenderly cared for by patient, selfless, insightful machines, may very well answer this question differently than we might today.[...] However, the important question isn't whether future generations will believe that machines are conscious, it's whether they will regard them as deserving of ethical consideration. If or when a new "race" of intelligent machines coexists alongside us, it's plausible that our descendants will feel that the moral courtesies we extend to other humans should also apply to certain nonbiological entities, regardless of their internal psychological composition.

\footnotetext{
${ }^{21} \mathrm{Cf}$. the classification of robots according to the criterion of autonomy (SAE 2018).

${ }^{22}$ There is even a label for this phenomenon: "gerontechnology" (Kwon 2016).
} 


\section{Should Al be endowed with legal subjectivity?}

The theses of this paper are firmly supported by Dremliuga et al. (2019):

There is no doubt that every legal person has to be recognized as such by society. [...] it is necessary for AI to have respect from human. Even famous Turing test has no legal meaning but it indicates that people tend to measure the personhood of a machine with the ability to be recognized by a person. This implies that people consider them as equal participants in social relations. [...] Described above cases do not imply that social recognition is necessary or enough for legal personhood, but it means that the lack of social recognition is a crucial obstacle for untypical legal persons. (Dremliuga et al. 2019, 109).

This obstacle will no doubt weaken over the course of time, as people notice and value AI entities more, because the development of AI's abilities let them interact more closely and AI systems become more present in everyday life.

Of course, there are other obstacles too. For example, Hildebrandt (2019) notices that:

The question of legal personhood for artificial agents clearly demonstrates that even if its attribution would solve some problems, it will create others. Many legal and other scholars warn that such attribution should not enable those who develop and employ artificial agents to outsource and escape responsibility, thus incentivizing them to take risks and externalise costs because they know they will not be liable.

Although this warning should be noted, it can be disregarded in the light of the facts described above. Firstly, such a danger can be avoided using the typical tools available to contemporary lawmakers. One such tool is to connect legal subjectivity with some financial autonomy of the entity, as is the case for legal partnerships, e.g., a limited liability partnership; in such a case, those who would benefit from the actions of AI would represent the source of financial means assuring this autonomy. Another instrument is to make insurance on AI activity obligatory, the price of which would depend on the failure rate of the AI. The above legislative means would have the additional beneficial result that because the liability would be integrated in one entity, i.e., the $\mathrm{AI}$, the problem of dividing liability among producer, user, trainer, data provider, and other entities engaged in the AI preparation would not exist. The injured party would not have to fight against many parties, but would have one entity to demand compensation from. One more possible tool would be attributing the liability for AI failure to those who are obliged to provide its maintenance.

Secondly, AI is purported to be more effective and less fallible than humans, and this checks out for now. As such, fewer cases for damage should be raised in certain domains than before AI was implemented. All the more because European legal rules demand safety and explainability by default.

Thirdly, if some kind of the Bundle Theory of Subjectivity (Kurki 2019) were to be accepted, it is possible to adjust the scope of subjectivity to practical needs, by only assigning the AI competences, claim rights or duties that are acceptable, useful, and safe. For example, my colleague Księżak and I (the article is in the course of writing) postulate that AI should be acknowledged as an author of its creative products according to copyright law, but only within the scope of narrowly-understood personal rights and possibly property rights, the latter only conditionally and adjusted in a special way.

In my opinion, endowing AI with some kind of subjectivity is inescapable and the earlier we start to think about it, the more ideas are possible. The process of changing the law does not have to be very fast. It should accompany technological and social change, because, as Bertolini who promotes sector-specific approach and ad hoc legislation very incisively puts it, "AI is a moving target" (Bertolini 2020, 15). But legal science should work on proposals as soon as possible, and not fall into ideological boost or simply guarding tradition.

Funding This work was supported by the National Science Centre, Poland under Grant Number UMO-2018/29/B/HS5/00421.

Open Access This article is licensed under a Creative Commons Attribution 4.0 International License, which permits use, sharing, adaptation, distribution and reproduction in any medium or format, as long as you give appropriate credit to the original author(s) and the source, provide a link to the Creative Commons licence, and indicate if changes were made. The images or other third party material in this article are included in the article's Creative Commons licence, unless indicated otherwise in a credit line to the material. If material is not included in the article's Creative Commons licence and your intended use is not permitted by statutory regulation or exceeds the permitted use, you will need to obtain permission directly from the copyright holder. To view a copy of this licence, visit http://creativecommons.org/licenses/by/4.0/.

\section{References}

Beran K (2020) The concept of juristic person. Wolters Kluwer, Prague Warsaw Bratislava Budapest

Bertolini A (2020) Artificial Intelligence and civil liability. Legal affairs. Policy department for citizen's rights and constitutional affairs directorate-general for internal policies, Brussels, PE 621.926 
Bostrom N (2014) Superintelligence. Paths, dangers, strategies. Oxford University Press, Oxford

Chen J, Burgess P (2019) The boundaries of legal personhood: how spontaneous intelligence can problematize differences between humans, artificial intelligence, companies and animals. Artif Intell Law. https://doi.org/10.1007/s10506-18-9229-x

Choi JJ, Kim Y, Kwak SS (2014) The autonomy levels and the human intervention levels of robots: the impact of robot types in humanrobot interaction. The 23rd IEEE International Symposium on Robot and Human Interactive Communication. https://doi. org/10.1109/roman.2014.6926394

Cohain JS, Buxbaum RE, Mankuta D (2017) Spontaneous first trimester miscarriage rates per woman among parous women with 1 or more pregnancies of 24 weeks or more. BMC Pregnancy Childbirth 17(1):437. https://doi.org/10.1186/s12884-017-1620-1

Dacey M (2017) Anthropomorphism as cognitive bias. Philos Sci. https ://doi.org/10.1086/694039

Dremliuga R, Kuznetcov P, Mamychev A (2019) Criteria for recognition of AI as a legal person. J Politics Law. https://doi. org/10.5539/jpl.v12n3p105

Finnis J (1987) On reason and authority in law's empire. 6 L. \& Phil, p 357. https://scholarship.law.nd.edu/law_faculty_scholarship/677

Finnis J (2011) Natural law and natural rights. Oxford University Press, Oxford New York

Hart HLA (1948-1949) The ascription of responsibility and rights. Proceedings of the Aristotelian Society. New Series 49. http:// www.jstor.org/stable/4544455

Hildebrandt M (2019) Legal personhood for AI? In: Law for Computer Scientists. https://lawforcomputerscientists.pubpub.org/ pub/4swyxhx 5

Hohfeld WN (1920) Fundamental legal conceptions as applied in judicial reasoning and other legal essays. Yale University Press, Yale. Reprinted by World Public Library Association 2010. http://www. christiananimism.com

Jońca M (2015/2016) "Źle urodzeni” a tradycja prawa rzymskiego ["Badly born" and the Roman law tradition]. Edukacja Prawnicza 2(164). https://www.edukacjaprawnicza.pl/zle-urodzeni-a-trady cja-prawa-rzymskiego/

Kaplan J (2016) Artificial Intelligence: What everyone needs to know. Oxford University Press, New York

Kowalski K (2017) Nowa Zelandia i Indie przyznały rację tubylcom: rzeki to żywe istoty. Powinny mieć osobowość prawną [New Zealand and India agree with indigenes: rivers are living creatures. They should have legal personhood], Rzeczpospolita 23.03.2017, https://www.rp.pl/Styl-zycia/303239855-Nowa-Zelandia-i-Indie -przyznaly-rzekom-osobowosc-prawna.html, access on 4 Aug 2020

Kraińska A (2018) Legal personality and artificial intelligence. newtech.law. 2 July 2018. Access on 2 Sep 2020. https://newtech.law/ en/legal-personality-and-artificial-intelligence/

Kramer MH (1998) Rights without trimmings. In: Kramer MH, Simmonds NE, Steiner H (eds) A debate over rights: philosophical enquiries. Oxford University Press, Oxford

Księżak P (2020) Zawieranie umów przez sztuczną inteligencję (AI). [Concluding contracts by artificial intelligence (AI)] In: Dumkiwicz M, Kopaczyńska-Pieczeniak K, Szczotka J (eds) Sto lat polskiego prawa handlowego. Księga jubileuszowa dedykowana Profesorowi Andrzejowi Kidybie. Vol. II, Wolters Kluwer, Warszawa

Kurki V (2019) The theory of legal personhood. Oxford University Press, Oxford

Kurki V, Pietrzykowski T (eds) (2017) Legal personhood: animals. Artificial Intelligence and the Unborn. Springer, Cham

Kwon S (2016) Gerontechnology. Research, practice, and principles in the field of technology and aging. Springer, New York

McCarthy J, Minsky ML, Rochester N, Shannon CE (1955) A proposal for the dartmouth summer research project on Artificial
Intelligence. http://www-formal.stanford.edu/jmc/history/dartm outh/dartmouth.html

Moyle W, Cooke M, Jones C, Klein B, Cook G, Gray C (2013) Exploring the effect of companion robots on emotional expression in older adults with dementia: a pilot randomized controlled trial. J Gerontol Nurs. https://doi.org/10.3928/009891134-20130313-03

Naffine N (2009) Law's meaning of life. Philosophy, religion, darwin and the legal person. Hart Publishing Ltd, Oxford

Obladen M (2016) From right to sin: laws on infanticide in antiquity. Neonatology. https://doi.org/10.1159/000440875

Ogleznev V (2016) Ascriptive speech act and legal language. SHS Web of Conferences 28. Available at SSRN: https://ssrn.com/abstr act $=2796007$

Oppy G, Dowie D (2020) The turing test. In: Zalta EN (ed) The stanford encyclopedia of philosophy. https://plato.stanford.edu.archi ves/fall2020/entries/turing-test/

Pietrzykowski T (2018) Personhood beyond humanism. Animals, chimeras, autonomous agents and the law. Springer, Cham

Plumwood V (2014) Nature in the active voice. In: Harvey G (ed) The handbook of contemporary animism. Routledge, New York

Radbruch G (1945) Five minutes of legal philosophy. Oxf J Stud 26(1):13-15

Robinson R (2018) The legal nature of the embryo: legal subject or legal object? Potchefsroomse Elektroniese Regsblad/Potchefsroom Electr Law J. https://doi.org/10.17159/1727-3781/2018/ v21i0a2914

Rowlands M (2012) Can animals be moral? Oxford University Press, Oxford

SAE (2018) SAE J3016 ${ }^{\mathrm{TM}}$ : taxonomy and definitions for terms related to on-road motor vehicle automated driving systems". https:// www.sae.org/news/press-room/2018/12/sae-international-relea ses-updated-visual-chart-for-its-"levels-of-driving-automation "-standard-for-self-driving-vehicles, 16.06.2018

Silver D, Schrittwieser J, Simonyan K et al (2017) Mastering the game of Go without human knowledge. Nature 550:354-359. https:// doi.org/10.1038/nature24270

Solaiman SM (2017) Legal personality of robots, corporations, idols and chimpanzees: a quest for legitimacy. Artif Intell Law 25(2):155-179

Teubner G (2018) Digital personhood? The status of autonomous software agents in private law (May 11, 2018). Available at SSRN: https://ssrn.com/abstract=3177096 orhttps://doi. org/10.2139/ssrn.3177096

Turing AM (2009) Computing machinery and intelligence. In: Epstein R, Roberts G, Beber G (eds) Parsing the Turing Test. Springer, Dordrecht. https://doi.org/10.1007/978-1-4020-6710-5_3

Urquiza-Haas E, Kotrschal K (2015) The mind behind anthropomorphic thinking: attribution of mental states to other species. Anim Behav 109:167-176

Van den Berg PAJ (2016) Slaves: persons or property? The Roman law on slavery and its reception in Western Europe and its overseas territories. Osaka Univ Law Rev 63. https://www.resea rchgate.net/publication/317400540_Slaves_persons_or_prope rty_The_Roman_law_on_slavery_and_its_reception_in_Weste rn_Europe_and_its_overseas_territories

Watts P (2006) Blindsight. Tor Books, New York

Wittgenstein L (2009) Philosophical Investigations. Translated by Anscombe GEM, Hacker PMS and Schulte J, Oxford: Blackwell, Revised 4th edition by Hacker PMS and Schulte J

Publisher's Note Springer Nature remains neutral with regard to jurisdictional claims in published maps and institutional affiliations. 